\title{
Making the OSCE More Effective: \\ Practical Recommendations from a Former Secretary General
}

\author{
Thomas Greminger"
}

\section{Abstract}

This contribution offers recommendations for strengthening the effectiveness of the OSCE based on the results of the "Fit-for-Purpose" reform agenda, which the author conducted during his term as Secretary General of the OSCE (2017-2020). While the OSCE is capable of reform, there is a clear need for further political engagement. The author recommends giving the Secretariat the space it needs to amend management processes and structures. Further recommendations include streamlining the budget process, providing executive structures with a timely budget and adequate resources, strengthening the Secretariat's capacity for strategic planning, encouraging coordination among executive structures, and updating the modalities of their programmatic work.

\section{Keywords}

OSCE, Secretariat, management, budget process, strategic planning

To cite this publication: Thomas Greminger, Making the OSCE More Effective: Practical Recommendations from a Former Secretary General, OSCE Insights 1/2021 (Baden-Baden: Nomos, 2022), https://doi.org/10.5771/9783748911456-01

\section{Introduction}

The OSCE is operating in a challenging political environment: trust in multilateral institutions and mechanisms for solv-

* Thomas Greminger

Federal Department of Foreign Affairs of Switzerland

E-mail: thomas.greminger@eda.admin.ch

Note: The views and opinions expressed in this contribution are the author's own and do not reflect the official position of Switzerland or of the Swiss Federal Department of Foreign Affairs (FDFA). This is not a publication of the FDFA. ing global problems is low, and unilateral and transactional approaches are prevailing. The polarization of key state actors in the Euro-Atlantic and Eurasian security area is deepening, violent conflicts are once again a reality in the OSCE area, arms control regimes are dissolving, and the risk of military incidents is rising. At the same time, we face a broad range of transnational threats that can only be effectively addressed through cross-border cooperation. These include terrorism and violent extremism, state and non-state cyber threats, trafficking in people, arms, cultural goods, and drugs, and challenges 
related to illegal migration. More recently, the security implications of climate and technological change (especially developments in artificial intelligence) have come to the fore. We are thus confronted with a paradox: while multilateral cooperation is being questioned and spaces for dialogue are shrinking, the need for cooperation and genuine dialogue is greater than ever. This situation is reflected in the OSCE.

If responding to modern security risks requires multilateral cooperation, how can we strengthen the OSCE as a forum for inclusive dialogue and a facilitator of effective security cooperation? What constraints does the organization face, and how can they be overcome? These questions were foremost on my mind when I began my term as Secretary General of the OSCE in 2017. Together with my Directors, and led by the newly created Strategic Policy Support Unit, we devised the "Fit-for-Purpose" agenda, which I presented to the participating States in February 2018. ${ }^{1}$ Three years on, the results are mixed. Analysis of the Fitfor-Purpose agenda's achievements shows that numerous changes have been implemented to increase the efficiency and effectiveness of the OSCE. The positive message for the future is that reform is possible. At the same time, however, essential reforms were stymied early on or have yet to cross the finish line. There is a clear need to sustain reform efforts to ensure that the OSCE remains capable of responding effectively to security challenges and makes efficient use of its limited resources.
This contribution to OSCE Insights focuses on four topics that the Fit-for-Purpose agenda addressed: ${ }^{2}$

- reviewing the management processes of the Secretariat;

- ensuring adequate resourcing for the OSCE;

- promoting the OSCE as a forum for inclusive dialogue; and

- enhancing programmatic cooperation.

I will briefly assess what has been achieved thus far and, where we have failed to reach set objectives, why this is so. In conclusion, I will offer recommendations to the participating States and the Secretariat.

\section{The achievements and failures of the Fit-for-Purpose agenda}

\section{The management review}

The OSCE Secretariat has grown organically since its establishment more than two decades ago. Its management processes have adapted in an ad hoc manner to new challenges, an increasing workload, participating States' changing priorities, and ever tighter budgets. In addition, new technologies and modern business practices have changed conditions of work. These developments created a need to systematically review the Secretariat's central management processes with an eye to increasing effectiveness and efficiency. For precisely this reason, I launched the Secretariat Management Review in April 2018, involving all Secre- 
tariat staff and supported by an international consulting firm. A total of eighty optimization steps were pursued. By July 2020 , sixty-eight had been implemented, five abandoned, and seven continued in separate processes. The implemented changes include:

- greater cost transparency through better control and reporting instruments;

- the introduction of a new travel management tool to reduce administrative workload and costs;

- a new online registration tool and conference management guide;

- a reduction of the administrative workload in procurement;

- a new electronic recruiting platform;

- online induction training for new OSCE employees and all staff; and

- revision of the approval process for extrabudgetary projects to differentiate between low- and high-risk projects and allow for an accelerated procedure.

Other areas where processes were optimized include logistics, building management, internal coordination, communication, and the digitalization of staff management and payment. There was a pattern to many of these changes: digital technology was introduced to improve service while cutting costs. Although the management review was originally designed not to cut costs but to redirect resources to increase added value, savings of around $€ 300,000$ were secured for 2019 alone. Shared service centres in areas such as information technology support and human resource administration, and a resource mobilization strategy for extrabud- getary contributions from state and nonstate actors and for in-kind donations are further initiatives almost ready for implementation.

Although the Secretariat Management Review focused on processes, it also considered organizational structure. In a quick win, the Records Management Unit merged with the OSCE Documentation Centre in Prague, and information communication technologies functions were consolidated in a specialized unit of the Department of Management and Finance. Other changes, however - such as making the Ethics Coordinator and the Gender Issues Programme directly accountable to the Secretary General were met with resistance from participating States and could not be implemented. Organizational changes such as these are reflected in the post table, which is part of the Unified Budget, and therefore require consensus. The same difficulty arose when I attempted to create the function of a second Deputy Head of the Secretariat. Since the OSCE does not want to fund a full-time Deputy Secretary General, the task of deputizing formally rests on the already busy Director of the Conflict Prevention Centre. I therefore appointed the Director of the Office of the Secretary General as second Deputy Head of the Secretariat. The division of tasks was clear: the Director of the Conflict Prevention Centre took on the deputy duties for external, conflict cycle-related business, while the Director of the Office of the Secretary General was responsible for internal, management-related issues. The practice worked perfectly and was never questioned by participating States. 
When I wanted to formalize it by amending the post table, a head of delegation launched a successful campaign against it and blocked the decision, arguing that the change had not been properly discussed with participating States.

I briefed heads of delegation thoroughly about the Secretariat Management Review and kept them updated through the Secretary General's hour and my small group meetings with ambassadors. The review was initially met with support and even enthusiasm from participating States, but interest in these managerial issues faded over time. In the budgetary discussions of the Advisory Committee on Management and Finance, little appreciation was shown for the resulting gains in efficiency and effectiveness. At the same time, a few states blocked well-argued organizational changes to the budget process, limiting the Secretary General's room for manoeuvre even in management matters. The participating States would do well to give the Secretariat some leeway and avoid micromanaging. They should instead focus on the political mechanics of achieving consensus and taking joint action based on common commitments.

The tendency for participating States to micromanage the Secretariat stands in sharp contrast to the assertion that management responsibility and competence are the undisputed core of the Secretary General's terms of reference. Paradoxically, the very states who have argued that the Secretary General is "only" the Chief Administrative Officer have not let the Secretary General perform that role unhindered. For my part, I observed that a clear majority of OSCE participating States prefer an active and diplomatically profiled Secretary General - and the Secretary General's mandate creates space for that. In practice, there are two areas that allow considerable scope for interpretation: one pertains to the Secretary General's political and diplomatic role; the other is the coordination that is incumbent on the Secretary General as Chief Administrative Officer. While the relevant Ministerial Council decisions offer a broad outline of the Secretary General's political tasks, ${ }^{3}$ it is the Chairperson-in-Office who ultimately defines the precise political scope of his or her activities. In my experience as Secretary General different Chairs placed different expectations on the Secretary General, to which the Secretary General has to adapt. The Secretary General's role as coordinator concerns both programmatic cooperation among executive structures and crisis management, as we witnessed during the COVID-19 pandemic. Effective coordination by the Secretariat is needed to ensure that two top objectives, duty of care and business continuity, are consistently pursued across the entire organization. With the increasing demand for interdisciplinary answers to complex security threats, the need for greater coordination of the OSCE's programmatic work is growing.

\section{Ensuring adequate resourcing}

In their policy statements, participating States consistently highlight the relevance of the OSCE as a forum for dialogue, 
a facilitator for managing and resolving conflict, and a provider of support for addressing security threats and implementing OSCE commitments. However, this does not automatically translate into providing the organization with adequate resources. There are quite a number of issues at stake. Here I will talk about the budget process, the size of the Unified Budget, the timing of its adoption and the scales of contribution. I will not go into issues related to extra-budgetary resources, even though they are highly relevant given their potential to significantly expand the resource base of the OSCE. The resource mobilization strategy mentioned above will have to include practices and rules for making more strategic use of current extra-budgetary contributions and tapping into new funding sources like aid agencies, international financial institutions and the private sector.

In principle, the need to reform the budget process is undisputed among participating States. The current process is complex, tedious, and protracted. It invites states to micromanage the financial affairs of the Secretariat and other executive structures and to link (often narrow) political and personal agendas to broader operational issues. A longer-term budget cycle would allow a more strategic approach to planning and better alignment of resources with political and mandated activities. In 2018, a proposal for budget reform drafted by the Secretariat was submitted to participating States. It contained two main elements: an extension of the Programme Outline from one to four years and the introduction of a two-year budget. The exact financial allocation would continue to be approved by the participating States annually. The proposal was well received. Even a key delegation voiced no fundamental resistance - after intensive preparatory work, including in its capital - although consent was made contingent on two essential requirements: the reform exercise had to be presented as a pilot and the Programme Outline limited to two years, since there was not enough confidence in the institutions to allow for a four-year plan.

The Italian Chairpersonship was about to submit the reform proposal to the Permanent Council for adoption shortly before the 2018 summer break, when a new obstacle appeared that ended up blocking this and other decisions proposed by the Secretariat for almost three quarters of a year. It concerned a matter totally unrelated to budget reform, the question of the so-called disclaimer. As this is typical of workings in the OSCE, I will offer some details.

In June 2018, a disclaimer was added to documents distributed to participating States through the official document distribution system, clarifying that the Secretariat bore no responsibility for their content. This was met with anger from one participating State, which suspected it to be a manoeuver against it by another. Indeed, several participating States had regularly complained to the Chairpersonship and the Secretariat that the document distribution system was being used abusively to share information from unrecognized de facto entities. Although the disclaimer was based on a decision 
by the Permanent Council and appeared on all documents in a non-discriminatory manner, the participating State in question insisted on perceiving it as an unfriendly act. Countless conversations with representatives at all levels - from the ambassador to the foreign minister could not convince it to withdraw its opposition. It was not until the first quarter of 2019 that the issue was resolved thanks to an intervention by the Chairperson-inOffice, Slovak Foreign Minister Miroslav Lajcak. This allowed other important processes to go forward, but the momentum of the budget reform could not be re-established. Stripped-down budget documentation and a more user-friendly Performance-Based Programme Report were all that remained of the first attempt at budget reform.

A second attempt was planned for 2020 , but here too, the window of opportunity opened late because the regular budget was not approved until May. In addition, the coronavirus crisis made conversations with participating States more difficult. Despite these challenges, the dialogue on a two-year budget and a multi-year Programme Outline resumed. The introduction of a longer-term capital investment plan seemed to gain traction, but the ensuing leadership crisis in July 2020 again dampened the drive for reform.

The scales of contributions, which define how much each of the fifty-seven OSCE participating States annually pay to the OSCE's regular budget, have been the subject of reform efforts for years. The key that determines the contributions of each state is complicated and out of date. Various attempts to modernize the scales of contributions and to adapt them to the current distribution of economic power have failed. Since one participating State in particular increasingly tied its budget approval to revising the contribution key, Chairpersonships were forced to take on the difficult task of trying to amend it. Although the amounts at stake are relatively small, the discussions have been politicized and in want of pragmatism. Chairs face an impossible task as long as major stakeholders remain unwilling to adjust the level of their contributions. It is therefore unfair to make approval of the Unified Budget conditional on revised scales of contributions. This is not to say that they should not be revised - quite the contrary. However, the problem cannot be solved on a purely technical level, as evidenced by the efforts of Slovakia when it chaired the OSCE in 2019. A solution would necessitate a significant investment of political capital by the Chair and a willingness to move forward on the part of the key stakeholders. At the same time, the technical details, while often minute, are important and difficult for high-ranking diplomats and officials in capitals, who only deal with such matters occasionally, to grasp. Perhaps this matter requires the attention of a former finance minister.

In 2020 , unperturbed by the pressure the coronavirus put on the functioning of the OSCE, participating States continued a lengthy and narrow-minded discussion for the approval of the 2020 Unified Budget, which should have been adopted by Christmas 2019. Despite the Chair's skillful leading of the process, the 
OSCE did not receive its regular budget until the end of May, i.e., with a fivemonth delay. Unfortunately, late budget approval is no longer the exception but the rule in the OSCE. Approval processes represent a heavy burden on any Chair and divert time, energy and attention of participating States from dealing with more substantive issues. They reduce the time available to discuss reform-related matters and massively complicate the smooth running of the organization. As long as there is no approved Unified Budget, operations must be financed through quarterly (and later monthly) allotments based on the budget of the previous year. Even worse, new programmatic activities are not allowed to start. Timely budget adoption is thus crucial to the effective functioning of the OSCE, and participating States should treat it as a strategic concern. Regular, desperate calls by Chairpersons-in-Office are not sufficient; a mechanism obliging states to adopt the Unified Budget on time must be implemented.

The lengthy 2020 Unified Budget discussions did not lead to an increase of funds. The result, for the ninth year in a row, was zero nominal growth. The OSCE is thus again losing around two per cent of its real purchasing power. Granted, any organization can stay afloat for some time under austerity measures, but there are limits to how long one can achieve more with less. These limits have clearly been exceeded by the executive structures of the OSCE after years of zero nominal growth and an increase in tasks, for example services for the benefit of the
Special Monitoring Mission to Ukraine (SMM).

Some states argue that the amount they are paying to the OSCE has increased since 2014 because the SMM has a separate budget which is almost as big as the Unified Budget. This is true, but what is forgotten is that the deployment of the SMM has significantly enlarged the workload in the Secretariat, with no corresponding augmentation of the Secretariat's budget. Thanks to efficiency gains due to the Secretariat Management Review and the more frequent charging of services to other executive structures, it has been possible to prevent major deficiencies in the fulfilment of mandates. However, the time has come for participating States to either reduce tasks substantially or discard the zero nominal growth dogma.

There is evidence that the same participating States that block approval for the Unified Budget can do things quite differently. The SMM budget was passed in good time in 2020 despite an increase of eight and a half per cent. State capitals showed a strong interest in securing the SMM's resources, and when risks such as delays in approving the budget in Vienna threatened, unmistakable political signals were given by the headquarters. Why the difference? I would argue that participating States accept the well-defined role of (and need for) the SMM. If the OSCE's Unified Budget were based on a clearer set of priorities agreed by participating States - perhaps at the level of foreign ministers - its adoption would proceed much more smoothly. As it stands, spoiling comes at a low cost to individual 
states but hurts the organization as a whole.

\section{Promoting the forum for inclusive dialogue}

One of the OSCE's strengths since its inception as the Conference on Security and Cooperation in Europe (CSCE) in 1975 is that it is a forum for inclusive dialogue. During the Cold War and again in the 1990s, the CSCE (renamed the OSCE in 1995) was a place for states to discuss and resolve a wide range of differences. As Chairperson of the Permanent Council in 2014 when Switzerland led the organization, and again when I served as Secretary General, my sense was that the culture of dialogue and cooperation was waning. OSCE meetings were being used to read speeches, score points, and engage in public diplomacy. Together with the OSCE Chairs, I sought to recapture and promote the organization's unique role as a space where fifty-seven non-likeminded countries can come together, engage in constructive dialogue, and build security through cooperation. Efforts under the Fit-for-Purpose agenda to revitalize dialogue in the OSCE were three-pronged: create a strategic planning capacity in the Secretariat, create additional opportunities for informal dialogue, and support the Structured Dialogue, the informal working group of participating States established by the Hamburg Ministerial Council in 2016 to discuss current and future challenges and risks to security.

When Switzerland held the OSCE Chair, I noticed that the Secretariat lacked the capacity to plan for the medium and long term because its policy and coordination units were absorbed with day-to-day business. Therefore, at the end of 2017, I established the Strategic Policy Support Unit, financed as an extrabudgetary project and staffed with experts seconded by the United States, the Russian Federation, the EU, and Switzerland. The aim was to bring greater continuity to the OSCE's planning processes and to better provide the Chair and the Troika (the current, past, and incoming Chairs) with strategic policy advice. The unit supported the 2019 and 2020 Chairs (Slovakia and Albania) in formulating their priorities, helped the Conflict Prevention Centre to develop regional strategic frameworks for the Western Balkans and Central Asia, produced recommendations for prospective Chairs of the OSCE, and studied the implications of relations with China for the OSCE. It also contributed to making the Programme Outline a more strategic document aligning the allocation of budget resources with policy priorities.

In addition to allocating regular budget means more strategically, it is equally important to devise OSCE's extra-budgetary activities in a more holistic way. They have been growing in size and are particularly relevant when it comes to innovation and new thematic accents set by the organization. With this aim in mind the position of a Strategic Planning and Resource Mobilization Coordinator (SPRM) has been created.

Strategic planning in the OSCE is a function of planning capacities in the Secretariat on the one hand and policy 
support and practice on the part of the Chairpersonship, the Troika, and participating States on the other. Although challenging, strategically aligning the political priorities defined by the Chairpersonship and the Troika is of the utmost importance. Each Chair tends to view the OSCE through the twelve-month lens of its leadership responsibilities. However, it would make sense to adopt a longer-term perspective, ideally in the form of a threeor four-year plan. When Finland chaired the OSCE in 2008, five consecutive chairs met as a quintet. Switzerland and Serbia agreed a joint work plan as successive Chairs in 2014 and 2015. Unfortunately, this model has not caught on. Currently, the prerequisites for longer-term planning exist, with the OSCE Chairs determined until 2023 (Sweden, Poland, and North Macedonia).

The OSCE's formal dialogue forums such as the Permanent Council and the Forum for Security Co-operation have largely become platforms for harsh, confrontational public diplomacy. The "Talking Points" series initiated under the Fitfor-Purpose agenda provided a new opportunity for informal dialogue. Experts were invited to the Secretariat premises to discuss new studies and publications with representatives of the participating States and OSCE staff. This was also an attempt to bring delegation members into the Secretariat. Another invaluable informal space for dialogue is the Security Days initiated by my predecessor, Lamberto Zannier. With the Strategic Planning Support Unit, I had the necessary capacity in the Secretariat to conceptualize such events in a targeted manner and to ensure consistent follow-up. Security Days have recently been held on issues such as the future of OSCE field operations, military incident prevention, sustainable development goals, technological change, and lessons of the Paris Charter.

I also encouraged think tanks to create informal space for dialogue on topical issues. At my suggestion, and with the political support of Miroslav Lajcak, a consortium formed by the Friedrich Ebert Foundation and GLOBSEC launched the Cooperative Security Initiative. The initiative aims to promote the concept of cooperative security in mainstream European security policymaking and generate new ideas for strengthening multilateralism and security cooperation in Europe.

The OSCE's Structured Dialogue, originally intended to stimulate arms control discussions, ${ }^{4}$ has in practice generated constructive exchanges on current threat perceptions, military postures, and measures to reduce tension. Participating States have also shown interest in using the forum to develop instruments to increase transparency, for example a template for major military exercises or a best practice guide for the prevention and management of military incidents.

I supported the Structured Dialogue to the best of my ability, especially in my interaction with governments and organizations like NATO, although participating States, in particular the Structured Dialogue sceptics among them, never tired of emphasizing that it is state owned and state driven. This stems from a fear of losing control over the process to the broad group of states supportive of the dialogue, to a 
committed Secretariat, and to interested think tanks and civil society organizations. The Structured Dialogue faces risks from its key stakeholders as well, who have mutually exclusive ideas about its priorities. In addition, maintaining its momentum has been challenging because a different participating State has chaired the informal working group each year. It is in need of new political motivation, decisive leadership, and a broader support base to increase its resilience. The latter could include parliamentarians, think tanks, the media, and civil society groups. The Structured Dialogue would also benefit from a more clearly defined vision of how the discussion should evolve and what topics it should cover.

\section{Enhancing programmatic cooperation}

The Fit-for-Purpose agenda aimed to enhance the OSCE's programmatic cooperation, including by mobilizing new donors and partners for cooperation. There is growing interest in the private sector in partnering with the OSCE and sponsoring its activities. Other non-traditional donors, such as international organizations and financial institutions, are also increasingly keen to support its programmatic work. The OSCE has to adapt its rules and working modalities if it wants to seize these opportunities. Efforts in this direction were kicked off under the Secretariat Management Review with the drafting of the resource mobilization strategy.

Alongside the programmatic departments of the Secretariat, the OSCE's field operations and institutions are essential for conducting its programmatic work. The good news about the field missions is that host country pressures on them have decreased significantly in recent years. This has a lot to do with the fact that we have succeeded in shaping the cooperation between the OSCE and host states as a partnership and in enhancing national authorities' sense of ownership with respect to field operations. Today the prevailing perception is that having the OSCE in the country is advantageous because it helps to implement important national reforms. In addition to strong local ownership, a clear profile and coordination with other international actors are important factors for the effectiveness and efficiency of the OSCE in the field.

OSCE field operations operate on the basis of the comprehensive approach to security and are required to develop activities in all three dimensions. Another comparative advantage of OSCE field presences is their proximity to government and their responsiveness to its wishes. However, both factors also expose the OSCE field activities to the constant risk of spreading their resources too thin. It is essential that heads of mission work closely with host states to build a clear and long-term plan for their activities. A multi-year strategy would enable defining where to concentrate expertise and invest the bulk of the resources. This would not entail being less responsive to government needs. It would sharpen the OSCE's profile in the country and make its added value clearer. Making the switch from the predominant "project" approach to a "programme" mindset may seem simple, but it requires a complete change of 
corporate culture among both Secretariat and field operations staff and donors. In the framework of the Secretariat Management Review, a number of management processes were adapted for this purpose. I also initiated a dialogue among the twelve major donors, with a view to introducing a sustainable programme culture.

Providing programmatic support to participating States that have an interest in cooperation but lack a formal OSCE presence is another challenge. Belarus, Armenia, and Azerbaijan undoubtedly fall within this category. With regard to the first two, there have already been initial attempts to integrate individual projects into the framework of a country programme. However, recent experience has revealed difficulties that require resolution based on general principles. Cooperation based exclusively on extrabudgetary financing is unsustainable, so at some point funds from the regular budget will have to be made available for such programmes. Even in the absence of a formal OSCE presence, rules defining the relation to the host state are needed. Without them, the OSCE cannot open a local bank account or protect its employees. Coordination among OSCE executive structures is necessary if the OSCE wants to establish a coherent country programme and conduct political dialogue with host authorities.

As outlined in the Fit-for-Purpose agenda, complex security challenges require interdisciplinary responses. This may require cooperation between different OSCE structures to mobilize different types of expertise and deliver a joint product. The EU-funded trial monitoring project in the Western Balkans, which will be implemented from 2021, is a perfect illustration of this: the OSCE will have a comparative advantage as an EU partner if it can combine the geographic context knowledge and the proximity to local governments of its field presences with the Office for Democratic Institutions and Human Rights' expertise in trial monitoring. This requires coordination by the Secretariat. The executive structures of the OSCE would therefore do well to cooperate in the spirit of the UN motto "Deliver as One". This is not the approach regularly voiced by participating States, however. The "autonomy of institutions" has become a mantra, and calls for cooperation and coordination among executive structures are rare. Yet the limits of that autonomy are all too evident when it comes to discussions on the budget or the appointment of heads of executive structures.

\section{Conclusions and recommendations}

Despite the mixed results of the Fit-forPurpose reform agenda, significant steps have been taken to increase the efficiency and effectiveness of executive structures. This shows that reform of the OSCE is possible. The following recommendations outline how participating States and executive structures could stimulate it further:

- Participating States should provide more space and support to the Secretariat and other executive structures to improve management processes and 
organizational structures and should refrain from micromanagement.

- Participating States should reform and simplify the budget process, ideally by introducing a biannual budget, a multi-year Programme Outline, and a capital investment plan.

- The OSCE Chair should discuss and agree in principle a revision of the scales of contributions with participating States who are key contributors on the political level.

- A mechanism ${ }^{5}$ that compels participating States to adopt the Unified Budget before Christmas should be introduced.

- Participating States should drop the zero nominal growth dogma and either provide the OSCE with adequate resources to fulfil its mandate or pursue a clearer and more limited set of priorities within a longer-term strategy. The OSCE cannot continue to do more with less.

- The strategic planning capacities of the Secretariat should be further consolidated, and strategic planning tools like the Programme Outline and a multi-year plan by an extended Troika further developed.

- Participating States should expand and make full use of informal forums for genuine dialogue. The Structured Dialogue should be strengthened by establishing a higher public profile, a two-year Informal Working Group chairpersonship and work plan, and should be made more resilient through academic/think tank/ civil society support.
- The profile and strategic outlook of field operations' programmatic portfolios should be sharpened. Managing countless small projects should be abandoned in favour of steering wellchosen programmes.

- Participating States should elaborate and agree on a general procedure for conducting programmatic work in participating States where the OSCE has no formal field presence. Country programmes could be financed by both the Unified Budget and extrabudgetary resources and operated through a technical presence under rules agreed with the host states.

- The rules should be amended and mind-sets changed to increase cooperation with non-traditional partners such as large regional organizations, international financial institutions, aid agencies, and private sector actors, including foundations.

In line with the recent "OSCE Call for Action" by more than fifty former OSCE leaders to step up "political-level engagement to ensure that the OSCE maintains its ability to continue addressing these [security] challenges effectively", ${ }^{6}$ I would encourage the Ministerial Council to agree on a "compact for a well-functioning organization". This would establish as matters of political concern objectives such as providing the OSCE with a timely and adequate budget, overcoming obstacles to adopting the agendas of routine meetings, and enabling reform. Such a compact would represent a political commitment to ensuring that the OSCE remains - or once again becomes - fit for purpose. 
Notes

At the Secretary General's hour of 14 February 2018, a non-paper outlining the ten points of the reform agenda was made available to participating States.

2 The reform agenda covered ten areas. This article focuses on selected thematic clusters. The author is currently working on a comprehensive assessment that will be published in 2021 .

3 The original mandate of the Secretary General was defined in Stockholm (1992). Ministerial Council Decisions from Porto (2002), Sofia (2004), Brussels (2006), and Vilnius (2011) provided the most important amendments. See, respectively: OSCE, Final Document of the Third Meeting of the CSCE Council of Ministers, Stockholm, 14-15 December 1992, 15 December 1992, https://www. osce.org/mc/40342; OSCE, Final Document of the Tenth Meeting of the OSCE Ministerial Council, Porto, 6-7 December 2002, 7 December 2002, https://ww w.osce.org/mc/40521; OSCE, Final Document of the Twelfth Meeting of the Ministerial Council, Sofia, 6-7 December 2004, 7 December 2004, https://www.osc e.org/mc/41813; OSCE, Final Document of the Fourteenth Meeting of the Ministerial Council, Brussels, 4 and 5 December 2006, 5 December 2006, https://ww w.osce.org/mc/25065; OSCE, Final Document of the Eighteenth Meeting of the Ministerial Council, Vilnius, 6-7 December 2011, 7 December 2011, https://www. osce.org/mc/88839
4 Article 3 of MC.DOC/4/16 tasked the Structured Dialogue as follows: “Today, in Hamburg, we commit ourselves to exploring, inter alia, how the negative developments concerning the conventional arms control and CSBM architecture in Europe can be reversed. Together, we will work towards creating an environment conducive to reinvigorating conventional arms control and CSBMs in Europe. The strong commitment of the OSCE participating States to full implementation and further development of arms control agreements is essential for enhancing military and political stability within the OSCE area." OSCE, From Lisbon to Hamburg: Declaration on the Twentieth Anniversary of the OSCE Framework for Arms Control, 9 December 2016, https:/www.osce.org/ch airmanship/289496

5 Creative ideas were put forward, for instance, by Romanian Minister of Foreign Affairs Teodor Melescanu at the 2019 Informal Ministerial Council in the High Tatras. He suggested that the Unified Budget should be submitted to the Ministerial Council in early December. Alternatively, good practices of other international organizations should be assessed.

6 OSCE PA, OSCE Call for Action: Reaffirming a Common Purpose, 4 December 2020, https://www.oscepa.org/documen ts/osce-call-for-action/4114-osce-call-for -action-reaffirming-a-common-purpose-e $\mathrm{ng} /$ file; also available as a flipping book, https://online.flippingbook.com/view/77 9749/ 
